Check for updates

Cite this: RSC Adv., 2019, 9, 36154

Received 29th August 2019

Accepted 29th October 2019

DOI: 10.1039/c9ra06866j

rsc.li/rsc-advances

\title{
A strained alkyne-containing bipyridine reagent; synthesis, reactivity and fluorescence properties $\uparrow$
}

\author{
Sam Forshaw, (D) a Richard C. Knighton, (D) a Jami Reber, ${ }^{a}$ Jeremy S. Parker, (D) b \\ Nikola P. Chmel (iD ${ }^{a}$ and Martin Wills ID $^{* a}$
}

\begin{abstract}
We report the synthesis of a bipyridyl reagent containing a strained alkyne, which significantly restricts its flexibility. Upon strain-promoted alkyne-azide cycloaddition (SPAAC) with an azide, which does not require a Cu catalyst, the structure becomes significantly more flexible and an increase in fluorescence is observed. Upon addition of $\mathrm{Zn}(\mathrm{II})$, the fluorescence is enhanced further. The reagent has the potential to act as a fluorescent labelling agent with azide-containing substrates, including biological molecules.
\end{abstract}

\section{Introduction}

Zinc is a vital trace element and is required in the basic cellular function of many biological organisms. ${ }^{1}$ In humans, proteins that bind zinc account for $c a .10 \%$ of all proteins, ${ }^{2}$ and zinc is the only transition metal found across all classes of enzymes. ${ }^{3}$ It is essential for important processes such as gene expression, ${ }^{4}$ neurotransmission, ${ }^{5}$ regulation of apoptosis ${ }^{6}$ and in reproduction. ${ }^{7}$ Maintenance of the correct intracellular levels of zinc is clearly requisite for critical cell functions. Indeed, misregulation of zinc in the brain is implicated in a range of neurological disorders such as epilepsy and Alzheimer's disease. ${ }^{4}$ Abnormal zinc levels are also intrinsically linked to cancer and are an important factor in apoptosis of malignant tumours. ${ }^{8}$ These factors have driven research into treatments or diagnostic tools for $\mathrm{Zn}(\mathrm{II})$, through the design of complexation agents and sensors. Molecules which modulate their fluorescence upon undergoing a reaction have the potential to selectively indicate the location of specific functional groups or analyte, for example azide- or alkyne-containing proteins or other synthetic molecules. ${ }^{9}$ Azido coumarin $\mathbf{1}$ is an example of a reagent which increases significantly in fluorescence upon cycloaddition with an alkyne. ${ }^{9 \boldsymbol{a}}$ In cases where the partner is a strained alkyne, ${ }^{\mathbf{1 0}}$ the cycloaddition reaction can take place without the need for a copper catalyst, ${ }^{11}$ which is highly advantageous in a biological setting due to its bioorthogonality (Scheme 1). ${ }^{\mathbf{1 1}}$

We, and others, have recently reported the synthesis and reactions of a strained alkyne of general structure 2 , derived from a biphenol backbone (Fig. 1). ${ }^{12}$ Although not as

\footnotetext{
${ }^{a}$ Department of Chemistry, The University of Warwick, Coventry, CV4 7AL, UK. E-mail: m.wills@warwick.ac.uk

${ }^{b}$ Early Chemical Development, Pharmaceutical Sciences, IMED Biotech Unit, AstraZeneca, Macclesfield, SK10 2NA, UK

$\dagger$ Electronic supplementary information (ESI) available: Experimental procedures, NMR and fluorescence spectra. See DOI: 10.1039/c9ra06866j
}

reactive as the more strained commercial reagents such as $\mathbf{3 - 5 , { } ^ { 1 0 , 1 1 }}$ it is simple to prepare via a short sequence, reacts with azides without a metal catalyst and has been demonstrated to be capable of forming synthetically-useful derivatives. We have also reported a dialkyne version of this reagent, i.e. $\mathbf{6}^{\mathbf{1 2 d}}$

Although strained alkynes such as 3-5 can be functionalised with a fluorescent group, ${ }^{13}$ we felt that it would be advantageous to design a reagent which could potentially gain fluorescence upon undergoing the cycloaddition reaction. Toward this end we designed reagent 7 , which contains a bipyridyl functional group, reasoning that its out-of-plane locking of the aryl rings by the inflexible alkyne would prevent fluorescence and eliminate the potential for metal chelation between the pyridiyl nitrogen atoms. However, upon cycloaddition with an azide, the rotation barrier about the biaryl $\mathrm{C}-\mathrm{C}$ bond should be decreased, increasing the propensity to become co-planar and thus become weakly emissive, which has the potential to increase further upon chelation of a suitable metal ion such as $\mathrm{Zn}$ (II), which are known to be highly emissive. ${ }^{\mathbf{1 4}}$ Related reagents based on the same dipyridyl scaffold have been reported, ${ }^{15}$ providing some precedent for our synthetic approach.

\section{Results and discussion}

The target reagent, 7, was prepared through a two-step process by first forming the known 2,2'-bipyridyl-3,3'-diol $\mathbf{8}^{\mathbf{1 6}}$ from iodopyridine 9 using a new protocol, and then cyclising the reagent through reaction with but-2-yne-1,4-diyl bis(4methylbenzenesulfonate), following our established protocol, to give 7 in $41 \%$ yield. The ${ }^{1} \mathrm{H}$ NMR spectrum of 7 exhibited diastereotopic $\mathrm{CH}_{2}$ resonances indicating conversion between atropisomers is slow on the NMR timescale $\left(500 \mathrm{MHz}, \mathrm{CDCl}_{3}\right.$, $298 \mathrm{~K}$ ). Correspondingly, it was found that compound 7 was not an effective bidentate ligand, likely due to the large $\mathrm{C}-\mathrm{C}$ biaryl torsional angle; our previous solid-state studies of biphenol 


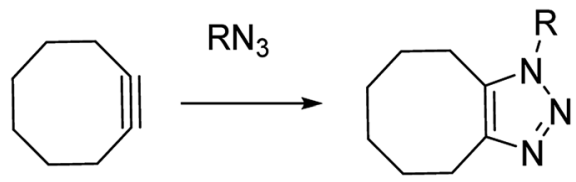<smiles>Nc1cc2ccc(O)cc2oc1=O</smiles>

Scheme 1 Uncatalysed reaction of azide with strained cyclooctyne, and a coumarin reagent which fluoresces upon undergoing a cycloaddition.<smiles>C1#CCOc2ccccc2-c2ccccc2OC1</smiles>

2<smiles>[R]C(=O)N1Cc2ccccc2C#Cc2ccccc21</smiles><smiles>[R]CC1C2CCC#CCCC12</smiles>

$3 \mathrm{BCN}$<smiles>[R]C1Cc2ccccc2C#Cc2ccccc21</smiles>

4 DIBO<smiles>C#CCOc1cccc(OC)c1C1=C2C=CC=C(OCC#CCO2)OCC#C1</smiles>

Fig. 1 Reported strained alkynes.

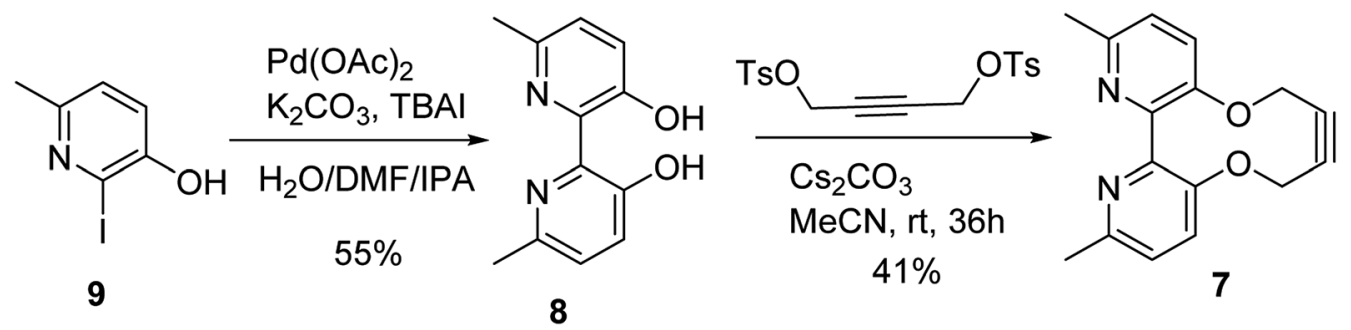

Scheme 2 Synthesis of 2,2-bipyridyl strained alkyne 7.

strained alkynes evidence significantly non-planar C-C biaryl bond dihedral angles (Scheme 2). ${ }^{12 a}$

The cycloaddition of 7 with benzylazide was studied (Scheme 3), using ${ }^{1} \mathrm{H}$-NMR to follow the changes in situ. The reaction took place without the requirement for a copper catalyst, generating the cycloadduct $\mathbf{1 0}$ in high yield over several days. The adduct 10 was qualitatively more fluorescent than the $2,2^{\prime}$ bipyridyl strained alkyne 7 , presumably due to the reduced<smiles>Cc1ccc(OCC#CCOc2ccc(C)nc2-c2cccnc2)c(C)n1</smiles><smiles>[NH2+]Cc1ccccc1</smiles><smiles>[R6]#N</smiles>
7<smiles>Cc1ccc(OCc2nnn(Cc3ccccc3)c2COc2ccc(C)nc2-c2ccccn2)c(C)n1</smiles>

Scheme 3 Cycloaddition of bipyridyl strained alkyne 7 with benzyl azide. The reaction was run with and without $\mathrm{ZnCl}_{2}$ in order to gauge its effect on the rate. 

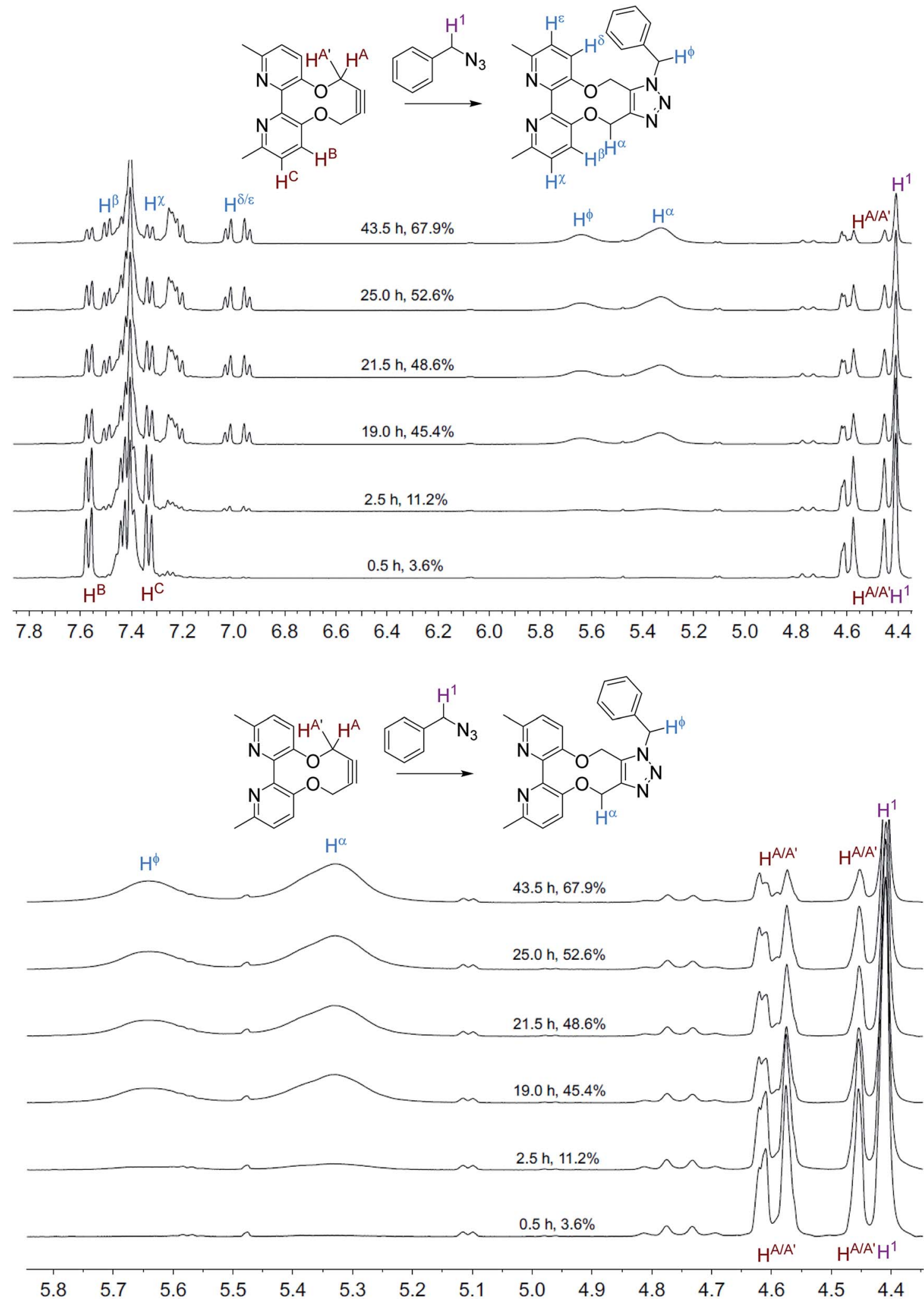

Fig. 2 Overlaid ${ }^{1} \mathrm{H}$ NMR spectra $\left(400 \mathrm{MHz}, \mathrm{CD}_{3} \mathrm{CN}, 298 \mathrm{~K}\right.$ ) for the cycloaddition reaction in Scheme 3 without added $\mathrm{ZnCl}_{2}$.

rotational restriction upon cycloaddition. The cycloaddition in the presence of $\mathrm{ZnCl}_{2}$ was slightly faster than in its absence and gave a significantly emissive adduct. It is unclear as to how the
$\mathrm{Zn}$ (II) accelerates the reaction however it is unlikely to chelate to the two pyridyl rings due to the likely wide torsion angle in the strained alkyne (vide supra). 

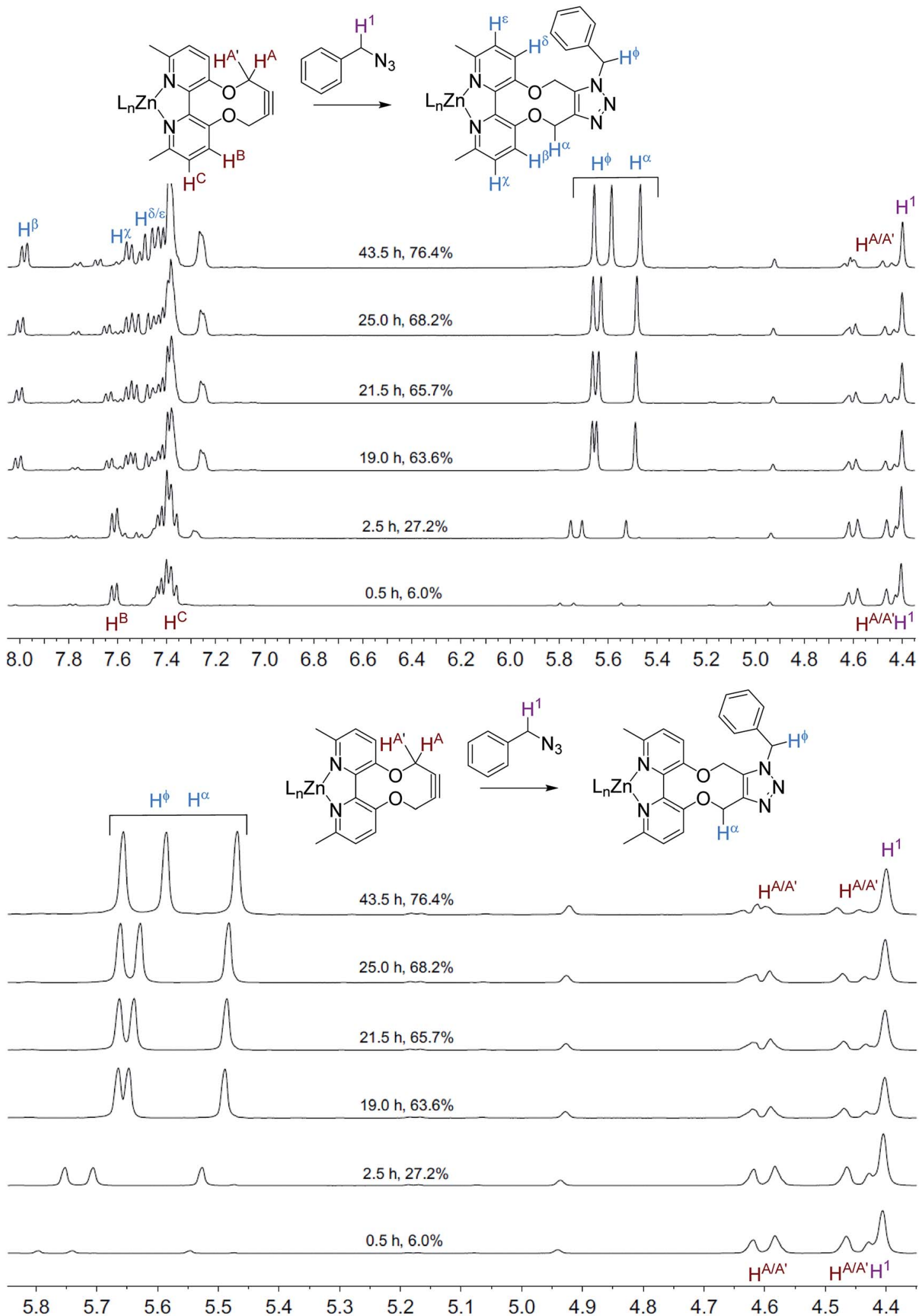

Fig. 3 Overlaid ${ }^{1} \mathrm{H}$ NMR spectra $\left(400 \mathrm{MHz}, \mathrm{CD}_{3} \mathrm{CN}, 298 \mathrm{~K}\right.$ ) for the cycloaddition reaction in Scheme 3 with added $\mathrm{ZnCl}_{2}$.

The NMR spectra, recorded at time intervals, of the cycloaddition without $\mathrm{ZnCl}_{2}$ are overlaid in Fig. 2; the product $\mathrm{CH}_{2}$ resonances are broad, indicating that the detected hydrogen atoms are alternating between different conformations due to restricted rotations on the NMR time scale, as previously observed for cycloadducts of this type. ${ }^{12} \mathrm{~A}$ variable temperature 


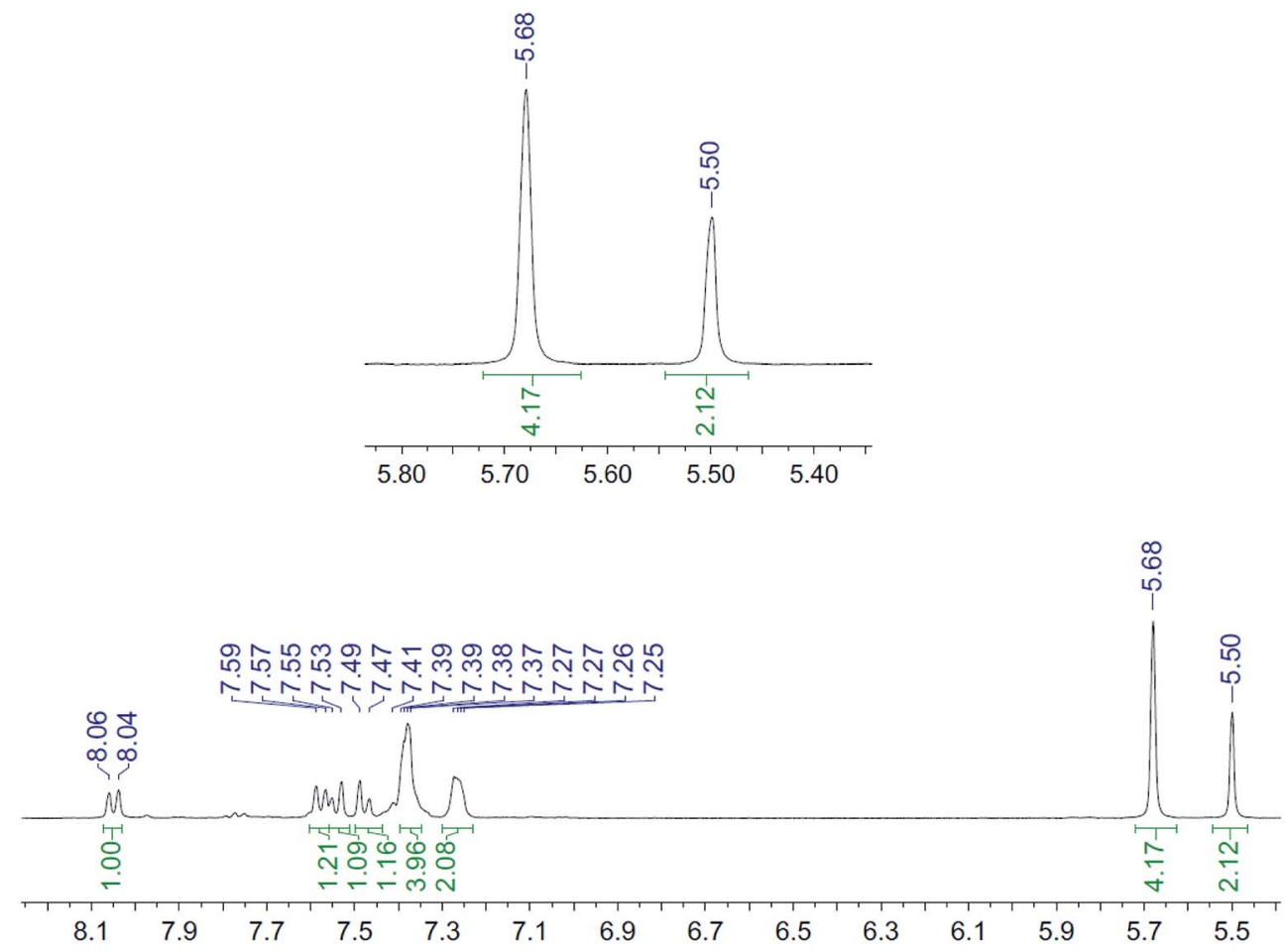

Fig. $4{ }^{1} \mathrm{H}$ NMR spectrum $\left(400 \mathrm{MHz}, \mathrm{CD}_{3} \mathrm{CN}, 298 \mathrm{~K}\right)$ for the uncomplexed addition product 10 after adding $\mathrm{ZnCl}_{2}$.

${ }^{1} \mathrm{H}$ NMR study of $\mathbf{1 0}\left(500 \mathrm{MHz}, \mathrm{CDCl}_{3}\right)$ revealed that the slow exchange of the atropisomers is reached at $243 \mathrm{~K}$, contrasting 7 which is resolved at ambient temperature, indicating greater flexibility of 10, however coalescence was not reached at $323 \mathrm{~K}$ (ESI $\dagger$ ).

The NMR spectra recorded, at each time interval, of the $\mathrm{ZnCl}_{2}$-complexed cycloaddition reaction are similarly overlaid in Fig. 3. In this case the product peaks were sharp, with three singlets being formed, corresponding to each of the $\mathrm{CH}_{2}$ groups in the product. In an independent test, $\mathrm{ZnCl}_{2}\left(1.0\right.$ eq., $\left.\mathrm{CD}_{3} \mathrm{CN}\right)$ was added to the uncomplexed NMR sample, resulting in sharp NMR peaks similar to the $\mathrm{Zn}$ (II)-complexed product 10 (Fig. 4).

It is unclear why the compound which had $\mathrm{Zn}$ (II) added before the cycloaddition reaction has three singlet peaks that each integrate to two hydrogens, while the compound which had $\mathrm{Zn}$ (II) added after the cycloaddition reaction has two singlet peaks, one of which integrates to four hydrogens and the other which integrates to two hydrogens. Since $\mathrm{Zn}$ (II) is able to form complexes with up to three bipyridyl compounds, this could be due to a different ratio of $\mathrm{Zn}(\mathrm{II})$ to bipyridyl in each sample. ${ }^{\mathbf{1 4}}$ The observations indicate that the $\mathrm{Zn}$ (II) complexation is likely to be responsible for the change in appearance of the NMR spectrum, possibly due to the flattening of the ring and reduction of the degrees of freedom (Fig. 5).

Whilst this $\mathrm{Zn}$ (II) complexation with a bipyridyl strained alkyne cycloaddition adduct is novel, $\mathrm{Zn}$ (II) complexation with bipyridyl compounds, to create highly fluorescent adducts, has been previously studied in detail. ${ }^{\mathbf{1 4}} \mathrm{Zn}$ (II) complexation has been shown to increase fluorescence intensity, a property which could potentially be beneficial for fluorescence-based reagents. The effect of $\mathrm{Zn}$ (II) complexation on fluorescence was also observed on both the cycloaddition bipyridyl product 10 and the precursor bipyridyl diol 8. All samples were made to the same concentration $\left(10^{-5} \mathrm{M}\right)$, and values were recorded at the same parameters on the same instrument (Fig. 6). The strained alkyne reagent 7 was also studied for comparison purposes.<smiles>Cc1ccc(OCc2nnn(Cc3ccccc3)c2COc2ccc(C)nc2-c2ccccc2)c(C)n1</smiles>

Uncomplexed has movement about biaryl C-C bond.

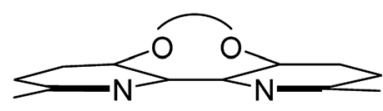

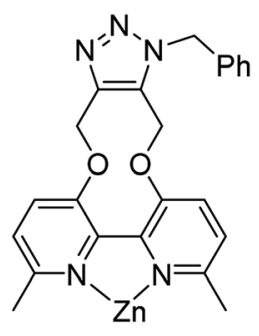

Flat (or almost flat) when co-ordinated to $\mathrm{Zn}(\mathrm{II})$.

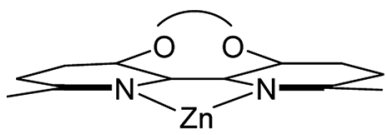

Fig. 5 Structures of uncomplexed and Zn(II)-complexed bipyridyl cycloaddition product 10. 

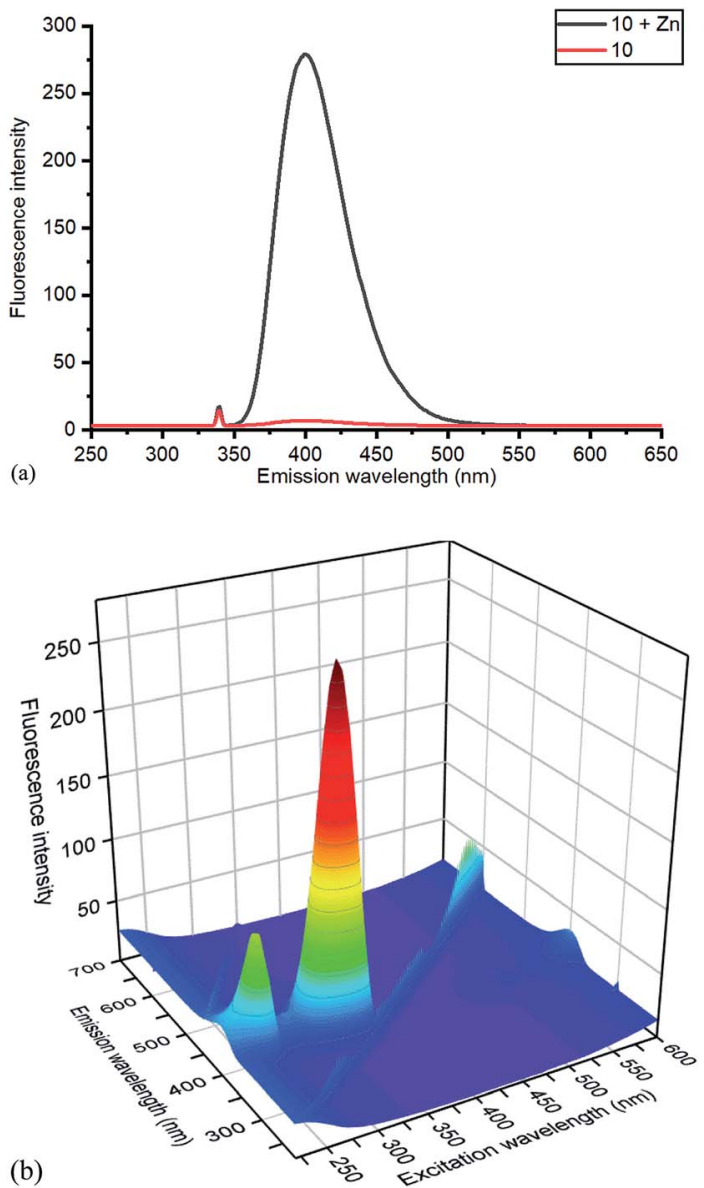

Fig. 6 (a) Emission spectra of 10 without and with added $\mathrm{ZnCl}_{2}$, with excitation at $340 \mathrm{~nm}$, and (b) 3D excitation vs. emission spectrum of $10 / \mathrm{ZnCl}_{2}$. The 3D spectrum of uncomplexed 10 is given in the ESI. $\dagger$

Based on relative intensity, cycloaddition product 10 showed a significant increase in fluorescence upon addition of $\mathrm{ZnCl}_{2}$ (Fig. 6) In contrast, addition of $\mathrm{Zn}$ (II) to the solution of 7 resulted in quenching of the fluorescence (ESI $\dagger$ ). This indicated that chelation of the metal was required for increased fluorescence, since the rigid structure of 7 prevents this. After observing the increase in fluorescence with $\mathrm{Zn}$ (II) for cycloaddition bipyridyl product 10, it was complexed with several other metal salts to investigate the selectivity of the system. The 3D fluorescence spectra were recorded for each of the metal complexes (Scheme

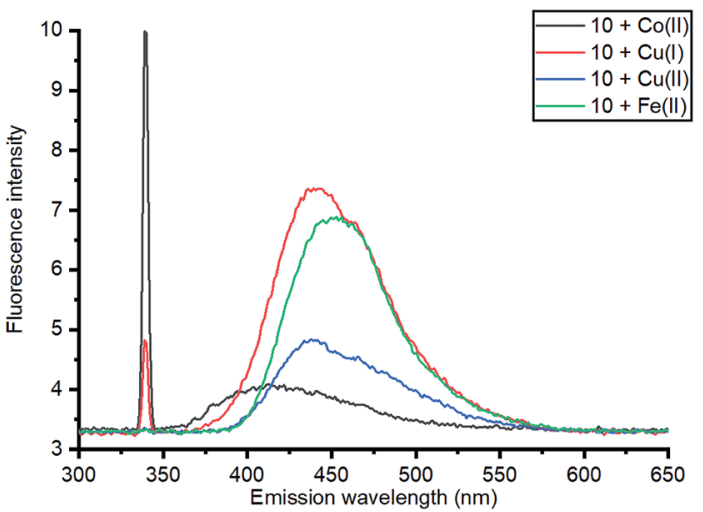

Fig. 7 Comparison of emission of complexes of 10 with a range of metals at $340 \mathrm{~nm}$ excitation; 3D and contour excitation vs. emission spectra are given in the ESI. $\dagger$

Table 1 Intensities at the maximum excitation and emission wavelengths for metal complexes of $10^{a}$

\begin{tabular}{lllll}
\hline & $\begin{array}{l}\text { Excitation } \lambda_{\max } \\
(\mathrm{nm})\end{array}$ & $\begin{array}{l}\text { Emission } \\
\lambda_{\max }(\mathrm{nm})\end{array}$ & Intensity & $\begin{array}{l}\text { Shift/ } \\
\mathrm{nm}\end{array}$ \\
\hline Uncomplexed 10 & 295 & 379 & 23 & 85 \\
10 Zn II complex & 341 & 400 & 279 & 59 \\
10 Cu I complex & 340 & 439 & 7 & 99 \\
10 Cu II complex & 345 & 438 & 5 & 93 \\
10 Co II complex & 325 & 450 & 6 & 75 \\
10 Fe II complex & 335 & 450 & 8 & 115 \\
a Spectra were recorded at a concentration of $10^{-5} \mathrm{M}$ in MeCN.
\end{tabular}

4, Fig. 7) The 3D and contour excitation $v s$. emission spectra are given in the $\mathrm{ESI} \dagger$.

The Zn(II)-complexed bipyridyl 10 exhibited a significantly higher fluorescence intensity compared to the other metal complexes; none of the other metals enhanced the fluorescence of the bipyridyl 10; moreover, the other metal complexes had lower emission intensities than even the uncomplexed bipyridyl 7. Table 1 summarises the combination of excitation and emission wavelength that gave the highest response as determined by 3D fluorescence spectroscopy, and the Stokes shifts. For comparison, the fluorescence of the $\mathrm{ZnCl}_{2}$-complexed and uncomplexed bipyridyl diol precursor $8^{\mathbf{1 7}}$ was also measured using 3D fluorescence spectroscopy (Fig. 8).

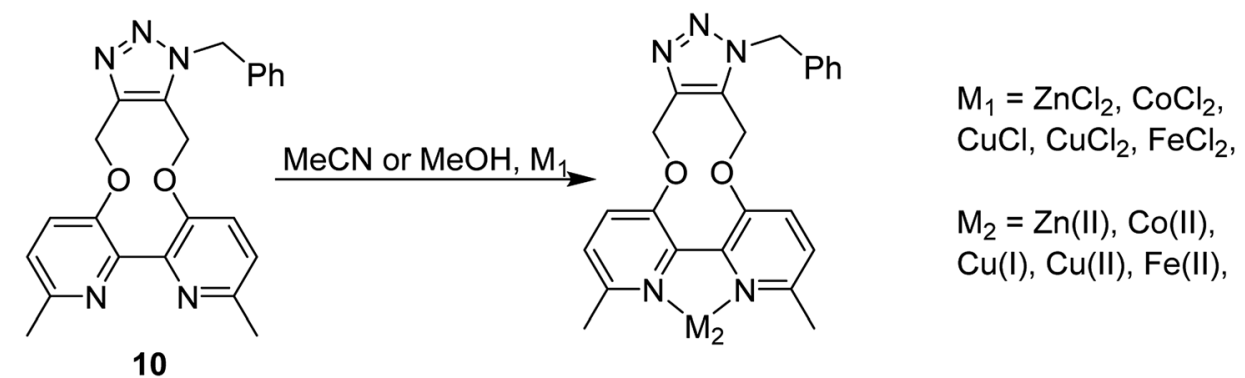

Scheme 4 Metal complexation with bipyridyl product 10. 


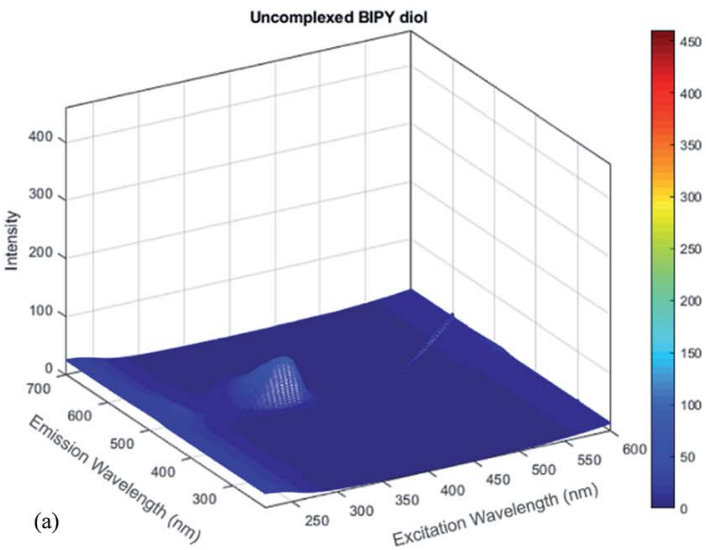

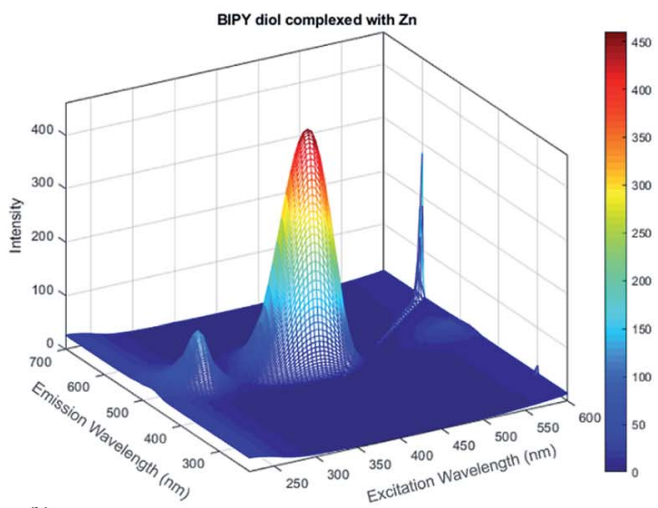

(b)

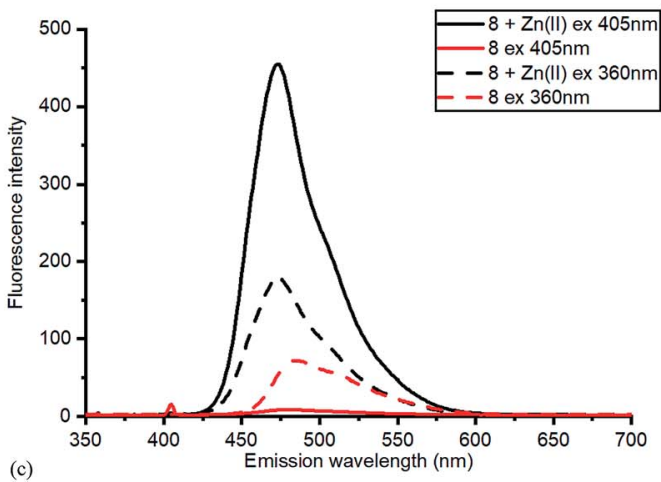

Fig. 8 Fluorescence spectra for diol 8 (a) without added $\mathrm{ZnCl}_{2}$ (b) with added $\mathrm{ZnCl}_{2}$. (c) Contrasting emissions at 405 and $360 \mathrm{~nm}$ excitation with and without added Zn(II).

Once again, the $\mathrm{Zn}(\mathrm{II})$ complexation caused a dramatic increase in the fluorescent intensity of the compound, although the selection of excitation wavelength was crucial in establishing the sharpest difference between the complexed and uncomplexed emission. With excitation at $405 \mathrm{~nm}$, sharply contrasting emission results were obtained compared to those at $360 \mathrm{~nm}$ excitation, where little difference was observed (Fig. 8c). The high fluorescence reflects efficient chelation of the $\mathrm{Zn}$ (II) by diol 8 .

\section{Conclusion}

In conclusion, we have prepared a new strained alkyne based on a bipyridyl dioxy backbone and have applied this to strainpromoted cycloaddition reactions with benzyl azide. Metal complexation is precluded on the alkyne compound 7 due to the rigidity and non-coplanarity of the bipyridine. Upon triazole formation, product $\mathbf{1 0}$ increases in conformational flexibility, allowing coordination to a range of transition and alkaline earth metals, as evidence by photophysical studies. Importantly, the fluorescence intensity increases significantly when $\mathrm{Zn}$ (II) salts are added to it, which is selective across the ranges of metals studied.

\section{Data sharing statement}

The research data (and/or materials) supporting this publication can be accessed at http://wrap.warwick.ac.uk/.

\section{Conflicts of interest}

The authors declare no conflicting interests.

\section{Acknowledgements}

We thank the EPSRC for support of RCK (EPSRC Project Grant EP/M006670/1) and EPSRC and Astrazeneca for support of SF through a National Productivity Investment Fund studentship. The authors thank Professor Mike Ward for helpful discussions.

\section{References}

1 (a) S.-H. Choi, K.-L. Lee, J.-H. Shin, Y.-B. Cho, S.-S. Cha and J.-H. Roe, Nat. Commun., 2017, 8, 15812; (b) J. M. Goldberg, F. Wang, C. D. Sessler, N. W. Vogler, D. Y. Zhang, W. H. Loucks, T. Tzounopoulos and S. J. Lippard, J. Am. Chem. Soc., 2018, 140, 2020-2023.

2 C. Andreini, L. Banci, I. Bertini and A. Rosato, J. Proteome Res., 2006, 5, 196-201.

3 M. R. Broadley, P. J. White, J. P. Hammond, I. Zelko and A. Lux, New Phytol., 2007, 173, 677-702.

4 J. Peng, W. Xu, C. L. Teoh, S. Han, B. Kim, A. Samanta, J. C. Er, L. Wang, L. Yuan, X. Liu and Y.-T. Chang, J. Am. Chem. Soc., 2015, 137, 2336-2342.

5 Y.-N. Wang, D. Figueiredo, X.-D. Sun, Z.-Q. Dong, W.-B. Chen, W.-P. Cui, F. Liu, H.-S. Wang, H.-W. Li, 
H. Robinson, E.-K. Fei, B.-X. Pan, B.-M. Li, W.-C. Xiong and L. Mei, Proc. Natl. Acad. Sci. U. S. A., 2018, 115, 2508-2513.

6 P. Makhov, K. Golovine, R. G. Uzzo, J. Rothman, P. L. Crispen, T. Shaw, B. J. Scoll and V. M. Kolenko, Cell Death Differ., 2008, 15, 1745-1751.

7 K. Kerns, M. Zigo, E. Z. Drobnis, M. Sutovsky and P. Sutovsky, Nat. Commun., 2018, 9, 2061.

8 (a) R. B. Franklin and L. C. Costello, J. Cell. Biochem., 2009, 106, 750-757; (b) J. S. Cristóvão, V. K. Morris, I. Cardoso, S. S. Leal, J. Martínez, H. M. Botelho, C. Göbl, R. David, K. Kierdorf, M. Alemi, T. Madl, G. Fritz, B. Reif and C. M. Gomes, Sci. Adv., 2018, 4, 1702.

9 (a) M. T. Gokmen, J. Brassinne, R. A. Prasath and F. E. Du Prez, Chem. Commun., 2011, 47, 4652-4654; (b) J.-J. Shie, Y.-C. Liu, J.-C. Hsiao, J.-M. Fang and C.-H. Wong, Chem. Commun., 2017, 53, 1490-1493; (c) C. Favre and F. Friscourt, Org. Lett., 2018, 20, 4213-4217; (d) E. Decuypère, M. Riomet, A. Sallustrau, S. Bregant, R. Thai, G. Pieters, G. Clavier, D. Audisio and F. Taran, Chem. Commun., 2018, 54, 10758-10761.

10 (a) J. Dommerholt, F. P. J. T. Rutjes and F. L. van Delft, Top. Curr. Chem., 2016, 374, 16; (b) C. G. Gordon, J. L. Mackey, J. C. Jewett, E. M. Sletten, K. M. Houk and C. R. Bertozzi, J. Am. Chem. Soc., 2012, 134, 9199-9208.

11 (a) Y. Gong and L. Pan, Tetrahedron Lett., 2015, 56, 21232332; (b) E. M. Sletten and C. R. Bertozzi, Angew. Chem., Int. Ed., 2009, 48, 6974-6998; (c) P. Thirumurugan, D. Matosiuk and K. Jowiak, Chem. Rev., 2013, 113, 49054979; (d) C. S. McKay and M. G. Finn, Chem. Biol., 2014, 21, 1075-1101.

12 (a) A. Del Grosso, L.-D. Galanopoulos, C. K. C. Chiu, G. J. Clarkson, P. B. O'Connor and M. Wills, Org. Biomol. Chem., 2017, 15, 4517-4521; (b) A. Mistry, R. C. Knighton,
S. Forshaw, Z. Dualeh, J. S. Parker and M. Wills, Org. Biomol. Chem., 2018, 16, 8965-8975; (c) T. Harris, G. d. P. Gomes, S. Ayad, R. J. Clark, V. V. Lobodin, M. Tuscan, K. Hanson and I. V. Alabugin, Chem, 2017, 3, 629-640; (d) R. C. Knighton, K. Sharma, N. S. Robertson, D. R. Spring and M. Wills, ACS Omega, 2019, 4, 2160-2167; (e) T. Harris and I. V. Alabugin, Mendeleev Commun., 2019, 29, 237-248.

13 (a) M. Boudiemeline, C. D. McNitt, T. A. Singleton, V. V. Popik and A. P. Kostikov, Org. Biomol. Chem., 2018, 10, 363-366; (b) J. Dommerholt, S. Schmidt, R. Temming, J. J. A. Hedriks, F. P. J. T. Rutjes, J. C. M. van Hest, D. J. Lefeber, P. Friedl and F. L. van Delft, Angew. Chem., Int. Ed., 2010, 49, 9422-9425; (c) J. M. Baskin, J. A. Prescher, S. T. Laughlin, N. J. Agard, P. V. Chang, I. A. Miller, A. Lo, J. A. Codelli and C. R. Bertozzi, Proc. Natl. Acad. Sci. U. S. A., 2007, 104, 16793-16797; (d) X. Ning, J. Guo, M. Wolfert and G.-J. Boons, Angew. Chem., Int. Ed., 2008, 47, 2253-2255.

14 (a) S. N. Ghosh, Inorg. Nucl. Chem. Lett., 1969, 5, 841-843; (b) W. L. Turnbull and L. G. Luyt, Chem.-Eur. J., 2018, 24, 1453914546; (c) L. Zhu, A. H. Younes, Z. Yuan and R. J. Clark, J. Photochem. Photobiol., A, 2015, 311, 1-15.

15 (a) K. Takaishi, J. Suzuki, T. Yabe, H. Asano, M. Nishikawa, D. Hashizume, A. Muranaka, M. Uchiyama and A. Yokoyama, Org. Lett., 2015, 17, 4098-4101; (b) T. Shimada, A. Kina and T. Hayashi, J. Org. Chem., 2003, 68, 6329-6337.

16 A. Reynal, J. Etxebarria, N. Nieto, S. Serres, E. Palomares and A. Vidal-Ferran, Eur. J. Inorg. Chem., 2010, 1360-1365.

17 G. Ulrich, F. Nastasi, P. Retailleau, F. Puntoriero, R. Ziessel and S. Campagna, Chem.-Eur. J., 2008, 14, 4381-4392. 